J. Dairy Sci. 92:3517-3528

doi:10.3168/jds.2008-1768

(C) American Dairy Science Association, 2009.

\title{
Reproductive status of Holstein and Jersey cows in the United States
}

\author{
H. D. Norman, ${ }^{1}$ J. R. Wright, S. M. Hubbard, R. H. Miller, and J. L. Hutchison \\ Animal Improvement Programs Laboratory, Agricultural Research Service, USDA, Beltsville, MD 20705-2350
}

\begin{abstract}
Reproductive information since 1995 from the USDA national dairy database was used to calculate yearly Holstein and Jersey means for days to first breeding after calving (DFB), 70-d nonreturn rate, conception rate $(\mathrm{CR})$, number of breedings per lactation (NB), interval between first and last breedings during the lactation, days to last breeding after calving (DLB), pregnancy rate $(\mathrm{PR})$, calving interval $(\mathrm{CI})$, and interval between consecutive breedings. Data were from nearly 20 million breedings during $>8$ million lactations of $>5$ million cows in $>23,000$ herds. Means were also calculated for some traits by parity and breeding number for both breeds and by geographical region and synchronization status for Holsteins. The DFB declined for Holsteins from 92 d in 1996 to 85 d in 2007; the trend in yearly differences was not as consistent for Jerseys. First- and all-breeding 70-d nonreturn rate declined 5 to 9 percentage units over time. First- and all-breeding $\mathrm{CR}$ declined 2 to 4 percentage units. The DFB were longer for later parities of Holsteins than for early parities. Second- and third-breeding CR were sometimes 1 to 2 percentage units above first-breeding CR for Holsteins but lower ( 1 to 7 percentage units) for Jerseys. The CR within breeding number declined across parities for both breeds. The NB increased by 0.3 to 0.4 breedings over time but remained constant (2.5 or 2.6 breedings) across parities for Holsteins and increased (from 2.2 to 2.4 breedings) for Jerseys. Holstein DFB were fewest in the Northwest $(78 \mathrm{~d})$ and greatest in the Mountain region (92 d). Regional CR was highest for the Northeast and Southwest (33\%) and lowest for the Southeast (26\%); NB was fewest for the Northeast (2.3) and greatest for the Southeast (2.7). Mean DLB was fewest for the Southwest $(127 \mathrm{~d})$ and greatest for the Mountain region $(157 \mathrm{~d})$; CI was shortest for the Southwest (406 d) and longest for the Mideast (434 d). Mean PR was highest for the Southwest (28.3\%) and lowest for the Mideast and Southeast (22.2\%). Use of timed artificial insemination following synchronized
\end{abstract}

Received September 30, 2008.

Accepted March 2, 2009.

${ }^{1}$ Corresponding author: Duane.Norman@ars.usda.gov estrus appears to have reduced $\mathrm{DFB}$, lowered $\mathrm{CR}$, and increased NB while reducing DLB and CI. However, synchronized breeding was not a primary cause of Holstein regional differences for reproductive traits. Since 2002, phenotypic performance for CR, DLB, and CI as well as genetic merit for daughter PR have stopped their historical declines and started to improve.

Key words: conception rate, nonreturn rate, reproduction, breeding

\section{INTRODUCTION}

Researchers have been concerned about the low fertility of milking herds for some time. Shanks and Freeman (1979) reported that $21 \%$ of direct health costs on dairies are for reproductive disorders, and insemination expenses accounted for an additional 19\%. Fertility had already been cited as one of the most frequent reasons for culling (O'Bleness and Van Vleck, 1962; Burnside et al., 1971; Van Vleck and Norman, 1972; Heimann, 1979). Berger et al. (1981) indicated that most dairy records processing centers (DRPC) routinely monitor calving interval (CI) and cited studies that showed this trait was increasing by $1 \mathrm{~d} / \mathrm{yr}$ in midwestern US herds; however, they noted the national trend in CI was unknown.

Some concern about the decline in fertility continued throughout the 1980s and 1990s. Annual summary tables calculated by DHI-Provo (B. H. Crandall, DHI Computing Service Inc., Provo, UT; personal communication) showed that mean days to first breeding (DFB) after calving increased from 82 to $86 \mathrm{~d}(5 \%)$ between 1990 and 1999; however, mean days from first breeding to conception (breeding period) increased from 47 to $68 \mathrm{~d}(45 \%)$. The DHI-Provo summaries indicated that number of breedings per lactation (NB) increased from 2.0 to 2.3 during the same period.

A review of studies on reproductive efficiency by Lucy (2001) revealed the validity of the concern about declining fertility. Washburn et al. (2002) reported large increases in days open (DO) and NB in herds in the southeastern United States during the 1990s. Recent national trend in DO has been confirmed (VanRaden et al., 2004; Hare et al., 2006) to be similar to that reported earlier by Berger et al. (1981) for midwestern US herds. 
De Vries and Risco (2005) reported that mean annual pregnancy rate (PR) declined from $22 \%$ in the late 1970 s to $12 \%$ in the early 2000 s for Holsteins that calved in Florida and Georgia. Although the percentage of US dairy operations with bulls has decreased slightly (54.6\% in 1996 to $51.7 \%$ in 2007 ; USDA, 2008), many dairy producers continue to use natural service as a method to manage cow fertility (Risco et al., 2008) despite the economic advantage of using AI (Hillers et al., 1982). Any significant reduction in AI use because of poor reproduction will reduce genetic gains and impede long-range benefits to producers and ultimately to consumers. A decline in fertility reduces the percentage of cows in their peak production period, which reduces herd milk yield. Lower fertility increases insemination costs and leads to increased involuntary culling (USDA, 2007). Norman et al. (2007) documented that unsatisfactory reproductive performance remains a primary reason for culling cows in each of the first 3 lactations.

The voluntary waiting period (VWP) is the period at the beginning of a lactation when cows are intentionally not inseminated, and it affects other reproductive events as well. The VWP from calving to first breeding differs among herds. Individual producers may even have different VWP depending on cow parity or milk yield during early lactation (DeJarnette et al., 2007). Use of bST on dairy farms has likely changed breeding practices in many herds as well.

Many studies (Olds et al., 1979; Berger et al., 1981; Laben et al., 1982; Faust et al., 1989; Clay and McDaniel, 2001; VanRaden et al., 2004) have shown an antagonistic relationship between milk yield and reproductive traits for lactating animals. That relationship appears to explain much of the decline in reproductive performance, because genetic merit for milk has increased by $120 \mathrm{~kg} / \mathrm{yr}$ (Animal Improvement Programs Laboratory, 2009a). A few studies, nevertheless, failed to reveal any antagonism; Hillers et al. (1984) reported no significant relationship, and Hansen et al. (1983b) reported a positive association between yield and fertility.

Compiling consistent national statistics on dairy cattle reproduction is a challenge because programs differ among DHI affiliates, partly from differences in data entry through various DRPC. Only about $50 \%$ of US dairy cows are enrolled in DHI (Animal Improvement Programs Laboratory, 2009b), and their owners choose the extent of their participation in herd management options. Data for several reproductive traits are available from DHI herds that record reproductive information, but CI and sometimes DO are the only reproductive traits available from the remaining DHI herds. Generally, reproductive data are not readily available from non-DHI herds even though estrus and breeding records could be obtained using on-farm computers. A few studies (Hansen et al., 1983a,b) have used breeding receipts created by AI technicians, but about $20 \%$ of US cows are not AI serviced (Norman et al., 2003). A uniform format to exchange reproductive data was developed by the Animal Improvement Programs Laboratory (2008) and is being used; therefore, standardization of reproductive data likely will increase.

Even though most fertility traits have low heritability estimates, the phenotypic variation for some traits is large and provides a favorable opportunity for selection (Philipsson, 1981). For example, reported DO means range from 94 to $148 \mathrm{~d}$ with a standard deviation (SD) of 46 to 82 d (Olds et al., 1979; Berger et al., 1981; Philipsson, 1981; Laben et al., 1982; Hansen et al., 1983a); heritability estimates for DO ranged from 2 to $6 \%$ (Berger et al., 1981; Philipsson, 1981; Hansen et al., 1983b; Hermas et al., 1987; VanRaden et al., 2004). In contrast, mean gestation length among US dairy breeds ranged from 278 to $287 \mathrm{~d}$ for heifers and 279 to $288 \mathrm{~d}$ for cows with an SD of 5 to $6 \mathrm{~d}$; heritability estimates for gestation length were 46 to $47 \%$ for service sire and 10 to $12 \%$ for cow sire for first parity and 33 to $36 \%$ and 7 to $12 \%$, respectively, for later parities (Norman et al., 2009). The economic value of fertility traits also is great (McGilliard, 1978; De Vries, 2006).

Pregnancy rate is defined as the percentage of nonpregnant cows that become pregnant during each 21-d period. It allows herd managers to know how soon cows become pregnant after having a calf. Many reproductive specialists prefer PR to DO as an indicator of reproductive success because PR is easily defined and available sooner and because nonpregnant cows are factored into its calculation (VanRaden et al., 2004). In addition, breeders are accustomed to having positive numbers reflect trait superiority.

An approximation of the PR calculated by DRPC is a nonlinear formula that converts DO to PR (VanRaden et al., 2004): PR $=[21 /(\mathrm{DO}-\mathrm{VWP}+11)] \times$ 100. Even though VWP varies within and across herds, making the assumption that VWP is fixed (e.g., $60 \mathrm{~d}$ ) permits comparisons to be made among animals. The constant 11 adjusts to the middle day of the 21-d cycle so that cows that conceive during the first cycle receive a PR of $100 \%$. For example, if VWP is assumed to be $60 \mathrm{~d}$, herds that average 70, 91, 112, 133, and $154 \mathrm{DO}$ have a PR of $100,50,33,25$, and $20 \%$, respectively.

Pregnancy rate and DO are nearly the same trait genetically. Although the formula for PR is nonlinear when graphed across the whole range of DO, the curve can be approximated by a straight line along the small range in daughter performance that reflects the genetic differences (VanRaden et al., 2004). When genetic evaluations are calculated, DO are converted to PR with a 
linear formula: $\mathrm{PR}=0.25(233-\mathrm{DO})$. Each increase in DO of $4 \mathrm{~d}$ reduces PR by $1 \%$.

In the United States, genetic evaluations for daughter PR (DPR) were initiated by the USDA in 2003 (VanRaden et al., 2004). Current US PTA for DPR are calculated using an all-breed animal model (VanRaden et al., 2007) and expressed as deviations from a base PR across breeds, which is then adjusted to a withinbreed base. The statistical model is the same as that used for yield traits, PL, and SCS, and a heritability of $4 \%$ is assumed for DPR (VanRaden et al., 2004).

The PTA for DPR are reported as percentages. A PTA DPR of 1 implies that a bull's daughters are 1\% more likely to become pregnant during that estrus cycle than if the bull had a PTA DPR of 0. A PTA for DO can be approximated as PTA DPR multiplied by -4 because each increase of $1 \%$ in PTA DPR is equivalent to a decrease of $4 \mathrm{~d}$ in PTA DO (VanRaden et al., 2004). Thus, a bull with a PTA DPR of +2.0 would have a PTA DO of -8 . A primary reason that DPR was chosen instead of DO as a genetic measure for cow fertility is the benefit of having a trait for which selection can be in a positive direction (such as for milk yield).

In 1990, an ad hoc committee of the American Association of Bovine Practitioners developed terminology and a set of proposed standards for measuring reproductive performance, which included the traits DO, $\mathrm{CI}, \mathrm{NB}$, and conception rate $(\mathbf{C R})$, on US dairy farms (Fetrow et al., 1990). The goal outlined by the committee was to set forth a basis for analyzing reproductive traits with consideration given to the availability of onfarm data, its electronic storage, and limitations of the computing environment.

Traits accessible for dairy research continue to expand as reproductive events reported through DHI increase with technological advances and improved computer capability. The goal of this study was to characterize DFB, 70-d nonreturn rate (NRR70), CR, NB, interval between first and last breedings during the lactation (breeding interval, BI), interval between calving and last breeding (days to last breeding, DLB), CI, interval between consecutive breedings, and PR using data not previously available on a national basis but now accessible through DHI for US Holsteins and Jerseys. Means for reproductive traits were summarized across time, and differences in reproductive performance associated with parity, breeding number, region, and synchronization status were documented for the most recent year with complete data reporting. Preliminary results from this study were available in 2003 and were helpful in determining that DPR was the most highly effective reproductive trait for which to initiate a genetic evaluation for female fertility (VanRaden et al., 2004).

\section{MATERIALS AND METHODS}

Breeding records from 1995 to 2008 for US Holstein and Jersey cows were obtained from herds participating in DHI and processed by 4 DRPC: AgriTech Analytics (Visalia, CA), AgSource Cooperative Services (Verona, WI), Dairy Records Management Systems (Raleigh, NC, and Ames, IA), and Pennsylvania DHIA (University Park, PA). Those 4 DRPC processed records for $81 \%$ of the cows and $91 \%$ of the herds that participated in DHI during 2002 (Animal Improvement Programs Laboratory, 2003). All records used in the study included service sire, sire, breeding number, DIM at each breeding, and parity. Records were from $>23,000$ herds, $>5$ million cows, $>8$ million lactations, and nearly 20 million breedings in 47 states and Puerto Rico.

Data for analysis were restricted to lactations with a first breeding before 365 DIM. Breedings to virgin heifers and to cows that left the herd before $70 \mathrm{~d}$ after first service were excluded. Herds were required to have $>9$ AI matings and $\geq 90 \%$ AI use per year so that herds with little information or incomplete data reporting were excluded. To eliminate herds that may have reported primarily (or only) successful inseminations, herds were required to have a mean CR of $\leq 75 \%$. Conception information used to calculate mean CR for a herd included first breedings for pregnant and open cows. If a subsequent breeding was within $10 \mathrm{~d}$ of an earlier breeding, only information from the later breeding was included.

Records for non-AI breedings were excluded because many of them were created from pregnancy diagnosis by veterinarians who estimated breeding dates from stage of fetal development. Because the number of non-AI breedings before a conception cannot be determined, including non-AI breeding records would result in overestimated NRR70 and CR for non-AI bulls. To determine if a conception resulted from an AI breeding, service sire identification was compared with information supplied by National Association of Animal Breeders (Columbia, MO).

To ensure that a cow had most subsequent breedings included, breedings that were $<70 \mathrm{~d}$ before July 18 , 2008, were excluded. The remaining records had breeding dates from January 1, 1995, to May 9, 2008. For some traits, data from 1995 and 2007 and 2008 were excluded because they were incomplete and would have biased results. Data for Holsteins and Jerseys were analyzed separately. National numbers of breeding records used for analysis are in Table 1 by reproductive trait and breeding year. Statistical probabilities were derived to assess both linear and quadratic (after linear) regression of year effects on reproductive traits. 
Table 1. Numbers of US Holstein and Jersey breeding records by breeding year and reproductive trait ${ }^{1}$

\begin{tabular}{|c|c|c|c|c|c|c|c|c|c|c|}
\hline Breed & $\begin{array}{l}\text { Breeding } \\
\text { year }\end{array}$ & DFB & \multicolumn{2}{|c|}{ NRR70 } & \multicolumn{2}{|c|}{$\mathrm{CR}$} & NB & BI & DLB & CI \\
\hline \multirow{10}{*}{ Holstein } & 1997 & 522,692 & 522,692 & $1,033,542$ & 458,975 & 943,497 & 475,133 & 475,132 & 318,756 & 203,020 \\
\hline & 1998 & 584,631 & 584,631 & $1,207,960$ & 519,027 & $1,127,851$ & 533,038 & 533,037 & 348,464 & 229,705 \\
\hline & 1999 & 615,821 & 615,821 & $1,290,920$ & 549,727 & $1,233,445$ & 562,919 & 562,918 & 356,349 & 240,910 \\
\hline & 2002 & 851,916 & 851,916 & $1,841,866$ & 751,806 & $1,830,577$ & 811,904 & 811,904 & 551,854 & 401,899 \\
\hline & 2003 & 931,578 & 931,578 & $2,105,863$ & 858,062 & $2,116,924$ & 894,671 & 894,665 & 662,452 & 470,349 \\
\hline & 2004 & $1,003,679$ & $1,003,679$ & $2,297,243$ & 944,635 & $2,360,158$ & 969,491 & 969,489 & 736,947 & 528,009 \\
\hline & 2005 & $1,059,340$ & $1,059,340$ & $2,517,406$ & 999,138 & $2,588,129$ & $1,024,436$ & $1,024,425$ & 762,885 & 533,562 \\
\hline & 2006 & $1,115,235$ & $1,115,235$ & $2,635,366$ & $1,032,506$ & $2,730,546$ & $1,080,009$ & $1,079,978$ & 803,193 & 567,318 \\
\hline & 2007 & $1,375,706$ & $1,375,706$ & - & $1,247,216$ & - & - & - & - & - \\
\hline & All years & $9,889,235$ & $9,889,235$ & $18,776,105$ & $8,981,223$ & $18,547,629$ & $8,033,564$ & $8,033,510$ & $5,589,391$ & $3,931,791$ \\
\hline \multirow{8}{*}{ Jersey } & 2001 & 46,599 & 46,599 & 90,565 & 41,051 & 88,590 & 43,021 & 43,016 & 26,777 & 18,598 \\
\hline & 2002 & 44,800 & 44,800 & 85,206 & 37,078 & 84,325 & 42,369 & 42,364 & 30,691 & 22,451 \\
\hline & 2003 & 47,705 & 47,705 & 95,880 & 42,938 & 96,246 & 45,561 & 45,552 & 36,118 & 25,481 \\
\hline & 2004 & 48,958 & 48,958 & 99,243 & 45,499 & 102,343 & 46,935 & 46,928 & 37,661 & 27,521 \\
\hline & 2005 & 51,870 & 51,870 & 109,989 & 48,262 & 112,012 & 49,884 & 49,879 & 40,155 & 28,430 \\
\hline & 2006 & 54,280 & 54,280 & 114,051 & 50,377 & 118,860 & 52,260 & 52,239 & 41,237 & 28,337 \\
\hline & 2007 & 90,071 & 90,071 & - & 78,448 & - & - & - & - & - \\
\hline & All years & 538,333 & 538,333 & 891,357 & 478,857 & 884,704 & 419,619 & 419,550 & 310,488 & 216,265 \\
\hline
\end{tabular}

${ }^{1} \mathrm{DFB}=$ days between calving and first breeding; NRR70 = nonreturn rate at $70 \mathrm{~d}$ after breeding; $\mathrm{CR}=$ conception rate; $\mathrm{NB}=$ number of breedings per lactation; $\mathrm{BI}=$ interval between first and last breedings; DLB $=$ days between calving and last breeding; and CI = calving interval.

Reproductive performance was characterized by 1) DFB, 2) NRR70 for each of the first 5 breedings within parity $(1,2, \ldots 5, \geq 6), 3) \mathrm{CR}$ for each of the first 5 breedings within parity $(1,2, \ldots 5, \geq 6), 4) \mathrm{NB}, 5) \mathrm{BI}$ in days, 6) DLB, 7) CI in days, 8) interval between consecutive breedings in days for the first 7 breedings (only intervals of $\leq 90 \mathrm{~d}$ were included for individual cows), and 9) PR. For NRR70, a breeding was considered to have been successful if the cow was not reported as rebred within $70 \mathrm{~d}$. Although CR may be a more useful variable than nonreturn rate of any length, NRR70 was included because of its widespread use in the past and because nonreturn rate is the primary reproductive variable available in many countries that supply reproductive information to the International Bull Evaluation Service (2009). For CR, a breeding was considered to have been successful if there was evidence that the cow became pregnant from that insemination. A breeding was coded as unsuccessful if a revealing reproductive event was reported after the breeding (e.g., a subsequent breeding or reported heat, a negative pregnancy examination, or a subsequent calving date not $280 \pm 14$ $\mathrm{d}$ after the reported breeding date) or if the cow left the herd with a termination code that indicated that she was sold for reproduction. A breeding was coded as suc- cessful if the subsequent calving date was $280 \pm 14 \mathrm{~d}$ after the reported breeding date. For the last reported lactation, a breeding was also coded as successful if a pregnancy examination confirmed conception.

Calving interval was determined through comparison of DRPC records with records in the USDA national dairy database. Days to last breeding were calculated from calving dates and last breeding dates.

Pregnancy rates were those calculated by USDA's Animal Improvement Programs Laboratory (VanRaden et al., 2004) for use in genetic evaluation. The USDA calculation uses a linear formula to convert DO to PR and excludes additional cycles after 250 DIM as well as lactations with no reported inseminations if the cow was sold during that lactation for reasons other than reproduction. Pregnancy status after 250 DIM is used, but a maximum of $250 \mathrm{DO}$ is imposed. For cows that become pregnant before 50 DIM, a minimum of $50 \mathrm{DO}$ is imposed. Records in progress and records with unverified pregnancies are included in national genetic evaluations for DPR but receive less weight than complete and verified records. The USDA PR are often somewhat higher than PR reported by DRPC and reproductive specialists, but DRPC PR were not available for comparison on a national basis. 
Table 2. Numbers of breeding records for US Holstein cows bred in 2006 by geographic region ${ }^{1}$ and reproductive trait ${ }^{2}$

\begin{tabular}{|c|c|c|c|c|c|c|c|}
\hline Region & DFB & $\begin{array}{l}\text { NRR70 for } \\
\text { first breeding }\end{array}$ & $\begin{array}{l}\text { CR for } \\
\text { first breeding }\end{array}$ & NB & DLB & CI & PR \\
\hline Mideast & 67,873 & 67,873 & 64,090 & 65,604 & 48,781 & 34,248 & 44,242 \\
\hline Midwest & 452,383 & 452,383 & 420,776 & 436,645 & 317,479 & 223,070 & 293,949 \\
\hline Northeast & 373,808 & 373,808 & 353,872 & 362,791 & 281,313 & 199,743 & 257,386 \\
\hline Northwest & 28,641 & 28,641 & 26,950 & 27,815 & 20,575 & 14,274 & 19,520 \\
\hline Southeast & 52,620 & 52,620 & 49,360 & 50,548 & 33,198 & 22,608 & 28,462 \\
\hline
\end{tabular}

${ }^{1}$ Mideast = Delaware, Kentucky, Maryland, North Carolina, Tennessee, Virginia, and West Virginia; Midwest = Illinois, Indiana, Iowa, Michigan, Minnesota, Missouri, Ohio, and Wisconsin; Mountain = Colorado, Kansas, Montana, Nebraska, North Dakota, South Dakota, Utah, and Wyoming; Northeast = Connecticut, Maine, Massachusetts, New Hampshire, New Jersey, New York, Pennsylvania, Rhode Island, and Vermont; Northwest $=$ Alaska, Idaho, Oregon, and Washington; Southeast = Alabama, Arkansas, Florida, Georgia, Louisiana, Mississippi, Oklahoma, Puerto Rico, South Carolina, and Texas; and Southwest = Arizona, California, Hawaii, Nevada, and New Mexico.

${ }^{2} \mathrm{DFB}=$ days between calving and first breeding; NRR70 = nonreturn rate at $70 \mathrm{~d}$ after breeding; $\mathrm{CR}=$ conception rate; $\mathrm{NB}=$ number of breedings per lactation; DLB = days between calving and last breeding; $\mathrm{CI}=$ calving interval; and $\mathrm{PR}=$ pregnancy rate.

To examine geographical differences, means and SD for DFB, NRR70 and CR after first breeding, NB, DLB, CI, and PR of Holstein cows first bred in 2006 were grouped using the regions defined by Hare et al. (2004). Numbers of breeding records by region and reproductive trait are in Table 2.

To document the extent of synchronized breeding (ovulation synchronization followed by timed AI) in the United States, Miller et al. (2007) developed a method to identify synchronized herds based on deviation of observed frequency of first breedings by day of the week from the expected equal frequency and by the maximum percentage of cows that were inseminated on a particular day of the week. Based on that method, Miller et al. (2007) categorized US herd-years according to likelihood of synchronized breeding: none, possible, probable, and definite. Holstein means and SD for DFB, NRR70 and CR after first breeding, NB, DLB, and CI were calculated by synchronized breeding status of the herd during 2006. Numbers of breeding records by herd synchronization status are in Table 3 . Use of synchronized breeding was also examined by region.

To examine changes in Holstein and Jersey genetic merit for DPR over time, breeding values from national genetic evaluations (Animal Improvement Programs
Laboratory, 2009a) on an all-breed genetic base (VanRaden et al., 2007) were compared for cow birth years from 1960 through 2005, the most recent birth year with complete data.

\section{RESULTS AND DISCUSSION}

National trends in reproductive traits of Holsteins and Jerseys from herds enrolled in DHI testing in the United States are shown in Table 4. Linear and quadratic year effects were significant $(P<0.001)$ for all traits except for quadratic effect of year on Jersey firstbreeding NRR70.

Mean DFB was lower for Holsteins in 2007 (85 d) than in 1996 (92 d). Means for Jersey DFB ranged from 83 to $88 \mathrm{~d}$, but the trend in yearly differences was not as consistent for Jerseys as for Holsteins. Regressions for both breeds showed an early increase followed by a decline, likely because of increased use of timed AI (Miller et al., 2007).

First-breeding NRR70 declined from $1996 \quad(54 \%$ for Holsteins and 57\% for Jerseys) to 2007 (45\% for Holsteins and $52 \%$ for Jerseys). Annual means for allbreeding NRR70 were lower than for first-breeding NRR70 by 1 to 3 percentage units for Holsteins and

Table 3. Numbers of breeding records for US Holstein cows bred in 2006 by herd synchronization status ${ }^{1}$ and reproductive trait ${ }^{2}$

\begin{tabular}{|c|c|c|c|c|c|c|}
\hline Herd synchronization status & DFB & $\begin{array}{l}\text { NRR70 for } \\
\text { first breeding }\end{array}$ & $\begin{array}{l}\text { CR for } \\
\text { first breeding }\end{array}$ & NB & DLB & CI \\
\hline Not synchronized & 527,549 & 527,549 & 485,134 & 509,762 & 380,202 & 265,274 \\
\hline Possibly synchronized & 89,109 & 89,109 & 82,257 & 86,704 & 64,143 & 45,778 \\
\hline Synchronized & 70,272 & 70,272 & 66,704 & 68,747 & 52,591 & 38,352 \\
\hline All herds & $1,031,400$ & $1,031,400$ & 958,692 & $1,000,962$ & 750,741 & 532,436 \\
\hline
\end{tabular}

${ }^{1}$ Herd synchronization (ovulation synchronization followed by timed AI) status determined using the method of Miller et al. (2007).

${ }^{2} \mathrm{DFB}=$ days between calving and first breeding; NRR70 = nonreturn rate at $70 \mathrm{~d}$ after breeding; $\mathrm{CR}=$ conception rate; $\mathrm{NB}=$ number of breedings per lactation; DLB = days between calving and last breeding; and CI = calving interval. 
Table 4. Means of US Holstein and Jersey reproductive traits ${ }^{1}$ by breeding year

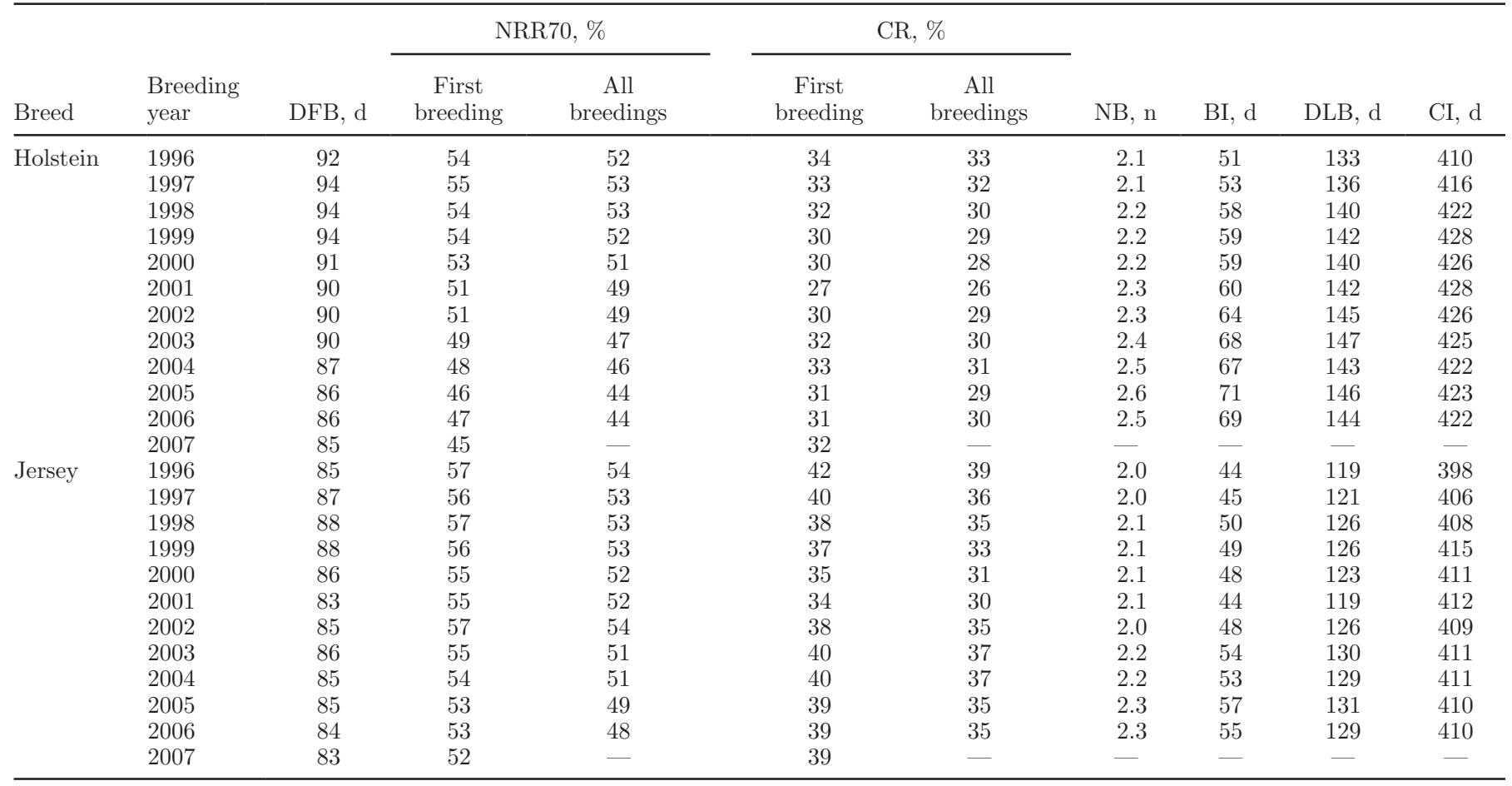

${ }^{1} \mathrm{DFB}=$ days between calving and first breeding; NRR70 = nonreturn rate at $70 \mathrm{~d}$ after breeding; $\mathrm{CR}=$ conception rate; $\mathrm{NB}=$ number of breedings per lactation; BI = interval between first and last breedings; DLB = days between calving and last breeding; and CI = calving interval.

3 to 5 percentage units for Jerseys. Mean all-breeding NRR70 in 2006 was $44 \%$ for Holsteins and $48 \%$ for Jerseys.

First-breeding CR was lowest in 2001 for both breeds (27\% for Holsteins and 34\% for Jerseys) but has improved since then. Mean first-breeding CR in 2007 was $32 \%$ for Holsteins and 39\% for Jerseys. Annual means for all-breeding CR were lower than for first-breeding CR by 1 to 2 percentage units for Holsteins and 3 to 4 percentage units for Jerseys. Mean all-breeding CR in 2006 was 30\% for Holsteins and 35\% for Jerseys.

Mean NB increased from 1996 (2.1 breedings per lactation for Holsteins and 2.0 breedings for Jerseys) to 2006 (2.5 breedings for Holsteins and 2.3 breedings for Jerseys). Mean Holstein BI increased by $18 \mathrm{~d}$ from $51 \mathrm{~d}$ in 1996 to $69 \mathrm{~d}$ in 2006. Mean Jersey BI was $11 \mathrm{~d}$ longer in 2006 (55 d) than in 1996 (44 d), but the trend in yearly differences was not as consistent for Jerseys as for Holsteins.

For both breeds, DLB and CI increased throughout the early years but have stabilized or are declining in recent years. In 2006, mean DLB was 144 d for Holsteins and $129 \mathrm{~d}$ for Jerseys; mean CI was $422 \mathrm{~d}$ for Holsteins and $410 \mathrm{~d}$ for Jerseys.

Mean DFB, DLB, CI, and NB for cows that were bred in 2006, the most recent breeding year with complete data, are in Table 5 by parity. For Holsteins, DFB increased with parity (from $85 \mathrm{~d}$ for parity 1 to $92 \mathrm{~d}$ for parities $\geq 6$ ). For Jerseys, DFB decreased from $86 \mathrm{~d}$ for parity 1 to $82 \mathrm{~d}$ for parities 2 and 3 and then increased to $88 \mathrm{~d}$ for parities $\geq 6$. Both linear and quadratic parity effects on DFB were significant $(P<0.001)$ for Holsteins, but only the quadratic effect was significant $(P<0.001)$ for Jerseys. Holstein DLB increased by 2 wk as parity increased (from $142 \mathrm{~d}$ for parity 1 to 156 d for parities $\geq 6$ ), but Jersey DLB increased by only 1

Table 5. Means of reproductive traits ${ }^{1}$ for US Holstein and Jersey cows bred in 2006 by parity of the lactation that ended the calving interval

\begin{tabular}{lccccc}
\hline Breed & Parity & DFB, d & DLB, d & CI, d & NB, n \\
\hline Holstein & 1 & 85 & 142 & - & 2.5 \\
& 2 & 85 & 143 & 420 & 2.6 \\
& 3 & 86 & 145 & 422 & 2.5 \\
& 4 & 88 & 148 & 422 & 2.5 \\
Jersey & 5 & 90 & 152 & 425 & 2.5 \\
& 26 & 92 & 156 & 432 & 2.6 \\
& 1 & 86 & 131 & - & 2.2 \\
& 2 & 82 & 125 & 412 & 2.2 \\
& 3 & 82 & 127 & 405 & 2.3 \\
& 4 & 83 & 128 & 408 & 2.3 \\
& 5 & 85 & 133 & 408 & 2.4 \\
& $\geq 6$ & 88 & 138 & 415 & 2.4 \\
\hline
\end{tabular}

${ }^{1} \mathrm{DFB}=$ days between calving and first breeding: $\mathrm{DLB}=$ days between calving and last breeding; $\mathrm{CI}=$ calving interval; and $\mathrm{NB}=$ number of breedings per lactation. 
Table 6. Means of 70-d nonreturn rate (NRR70) for US Holstein and Jersey cows bred in 2006 by parity of the lactation that ended the calving interval and breeding number

\begin{tabular}{lcccccc}
\hline & & \multicolumn{5}{c}{ NRR70, $\%$} \\
\cline { 3 - 6 } Breed & Parity & $\begin{array}{c}\text { First } \\
\text { breeding }\end{array}$ & $\begin{array}{c}\text { Second } \\
\text { breeding }\end{array}$ & $\begin{array}{c}\text { Third } \\
\text { breeding }\end{array}$ & $\begin{array}{c}\text { Fourth } \\
\text { breeding }\end{array}$ & $\begin{array}{c}\text { Fifth } \\
\text { breeding }\end{array}$ \\
\hline Holstein & 1 & 48 & 45 & 43 & 41 & 39 \\
& 2 & 46 & 43 & 42 & 40 & 39 \\
& 3 & 45 & 43 & 43 & 41 & 40 \\
& 4 & 46 & 43 & 43 & 41 & 40 \\
Jersey & 5 & 46 & 43 & 43 & 41 & 40 \\
& 2 & 45 & 44 & 43 & 41 & 40 \\
& 1 & 53 & 52 & 49 & 46 & 37 \\
& 2 & 54 & 49 & 44 & 42 & 34 \\
& 3 & 52 & 49 & 47 & 41 & 38 \\
\hline
\end{tabular}

wk ( $131 \mathrm{~d}$ for parity 1 to $138 \mathrm{~d}$ for parities $\geq 6$ ). Parity effects on DLB were significant $(P<0.001$ for Holstein linear and quadratic effects and for Jersey quadratic effects; $P<0.05$ for Jersey linear effects). Mean Holstein CI were $12 \mathrm{~d}$ shorter $(P<0.001)$ for parity 2 than for parities $\geq 6$. In Jerseys, only the quadratic effect on CI was significant $(P<0.001)$, which indicated that CI was shorter for intermediate parities than for first or later parities. Mean NB remained reasonably consistent (2.5 or 2.6; nonsignificant linear effect and $P<0.001$ for quadratic effect) for Holsteins across parities but increased slightly for Jerseys (from 2.2 to $2.4 ; P<0.001$ for linear effect and $P<0.05$ for quadratic effect).

Mean NRR70 for parity-breeding number subsets for cows bred in 2006 (Table 6) ranged from 39 to $48 \%$ for Holsteins and from 34 to $54 \%$ for Jerseys. Mean NRR70 decreased consistently within parity as breeding number increased for both breeds (5 to 9 percentage units for Holsteins and 11 to 17 percentage units for Jerseys).
All linear effects of breeding number within parity on NRR70 were significant $(P<0.001)$, but quadratic effects were significant only for Holstein parities $1(P<$ $0.001), 2(P<0.05)$, and $\geq 6(P<0.01)$ and Jersey parity $5(P<0.05)$. No consistent trend in NRR70 across parities for each breeding number was observed for Holsteins; mean NRR70 declined 3 percentage units across parities for first breedings and 1 percentage unit for second breedings, did not change for third and fourth breedings, and increased by 1 percentage unit for fifth breedings. However, Jersey NRR70 declined across parities: 2 percentage units for first breedings, 5 percentage units for second breedings, 8 percentage units for third breedings, 3 percentage units for fourth breedings, and 7 percentage units for fifth breedings. All linear effects on NRR70 across parities were significant $(P<0.001)$ except for Holstein second breedings; quadratic effects were significant for all Holstein breedings except fifth $(P<0.001$ for first through third

Table 7. Means of conception rate (CR) for US Holstein and Jersey cows bred in 2006 by parity of the lactation that ended the calving interval and breeding number

\begin{tabular}{lcccccc}
\hline & \multicolumn{5}{c}{ CR, $\%$} \\
\cline { 3 - 6 } Breed & Parity & $\begin{array}{c}\text { First } \\
\text { breeding }\end{array}$ & $\begin{array}{c}\text { Second } \\
\text { breeding }\end{array}$ & $\begin{array}{c}\text { Third } \\
\text { breeding }\end{array}$ & $\begin{array}{c}\text { Fourth } \\
\text { breeding }\end{array}$ & $\begin{array}{c}\text { Fifth } \\
\text { breeding }\end{array}$ \\
\hline Holstein & 1 & 34 & 33 & 31 & 28 & 26 \\
& 2 & 30 & 30 & 30 & 28 & 26 \\
& 3 & 29 & 30 & 29 & 28 & 26 \\
& 4 & 28 & 29 & 29 & 27 & 26 \\
Jersey & 5 & 26 & 27 & 28 & 26 & 25 \\
& 26 & 24 & 26 & 26 & 33 & 30 \\
& 1 & 40 & 39 & 36 & 31 & 29 \\
& 2 & 41 & 36 & 35 & 31 & 26 \\
& 3 & 39 & 35 & 33 & 29 & 26 \\
\hline
\end{tabular}


Table 8. Numbers of consecutive breedings and mean interval between consecutive breedings for US Holstein and Jersey cows bred in 2006 by breeding number

\begin{tabular}{llrc}
\hline Breed & Breeding numbers & $\begin{array}{c}\text { Breedings, } \\
\mathrm{n}\end{array}$ & $\begin{array}{c}\text { Interval between } \\
\text { breedings, }{ }^{1} \mathrm{~d}\end{array}$ \\
\hline Holstein & 1,2 & 583,739 & 39.3 \\
& 2,3 & 373,777 & 38.4 \\
& 3,4 & 233,555 & 37.6 \\
& 4,5 & 146,858 & 36.9 \\
& 5,6 & 92,460 & 36.1 \\
Jersey & 6,7 & 58,412 & 35.6 \\
& All breedings & $1,488,801$ & 38.2 \\
& 1,2 & 24,913 & 36.1 \\
& 2,3 & 14,675 & 35.7 \\
& 3,4 & 8,656 & 34.8 \\
& 4,5 & 5,394 & 34.4 \\
& 5,6 & 3,389 & 34.4 \\
& 6,7 & 2,216 & 34.3 \\
\hline
\end{tabular}

${ }^{1}$ Maximum interval of $90 \mathrm{~d}$.

breedings; $P<0.05$ for fourth breedings) but only for Jersey second breedings $(P<0.05)$.

Mean CR for parity-breeding number subsets for cows bred in 2006 (Table 7) ranged from 24 to $34 \%$ for Holsteins and from 25 to $40 \%$ for Jerseys. Mean Holstein CR within parity increased or stayed the same through second or third breedings and then began to decrease except for parity 1 , which had decreasing CR after first breeding. All Jersey CR within parity decreased as breeding numbers increased. Mean Jersey CR within parity was 1 to 7 percentage units lower for second and third breedings than for first breedings. Holstein and Jersey CR for parity 1 decreased by 7 and 11 percentage units, respectively, from second to fifth breedings. Corresponding CR decreases were 1 to 4 percentage units for later Holstein parities and 6 to
10 percentage units for later Jersey parities. All linear effects of breeding number within parity on CR were significant $(P<0.001$ for Holstein parities 1 through 3 and all Jersey parities, $P<0.05$ for Holstein parity 4) except for Holstein parity 5; quadratic effects were significant for all Holstein parities $(P<0.001)$ but only Jersey parity $1(P<0.01)$. Mean $\mathrm{CR}$ within breeding number declined across parities for both breeds: For Holsteins, CR decreased by 10 percentage units for first breedings, 7 percentage units for second breedings, 5 percentage units for third breedings, 3 percentage units for fourth breedings, and 1 percentage unit for fifth breedings; corresponding decreases for Jerseys were 7, $8,8,7$, and 3 percentage units. All linear effects on CR across parities were significant $(P<0.001$ for Holstein and Jersey first through fourth breedings; $P<0.01$ for

Table 9. Means and SD for reproductive traits ${ }^{1}$ of US Holstein cows bred in 2006 by geographic region ${ }^{2}$

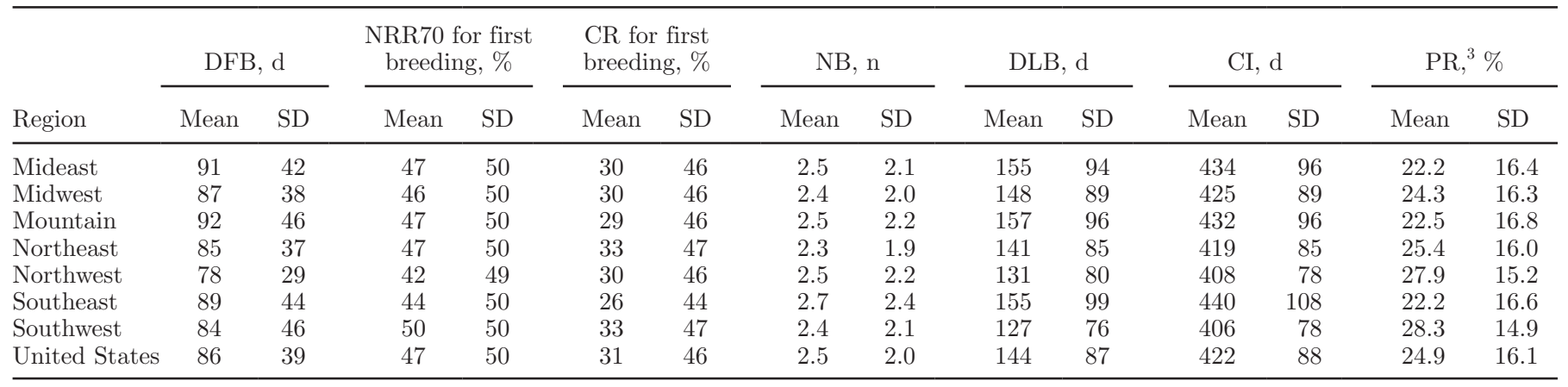

${ }^{1} \mathrm{DFB}=$ days between calving and first breeding; NRR70 = nonreturn rate at $70 \mathrm{~d}$ after breeding; $\mathrm{CR}=$ conception rate; NB $=$ number of breedings per lactation; DLB = days between calving and last breeding; and CI = calving interval.

${ }^{2}$ Mideast $=$ Delaware, Kentucky, Maryland, North Carolina, Tennessee, Virginia, and West Virginia; Midwest = Illinois, Indiana, Iowa, Michigan, Minnesota, Missouri, Ohio, and Wisconsin; Mountain = Colorado, Kansas, Montana, Nebraska, North Dakota, South Dakota, Utah, and Wyoming; Northeast = Connecticut, Maine, Massachusetts, New Hampshire, New Jersey, New York, Pennsylvania, Rhode Island, and Vermont; Northwest = Alaska, Idaho, Oregon, and Washington; Southeast = Alabama, Arkansas, Florida, Georgia, Louisiana, Mississippi, Oklahoma, Puerto Rico, South Carolina, and Texas; and Southwest = Arizona, California, Hawaii, Nevada, and New Mexico.

${ }^{3}$ Pregnancy rate (PR) is calculated as $100(0.25)(233$ - days open) with days open limited to $\geq 50$ or $\leq 250$. 
Table 10. Herd synchronization status ${ }^{1}$ of US Holstein herds for 2006 breedings by geographic region ${ }^{2}$

\begin{tabular}{|c|c|c|c|c|c|c|c|c|c|}
\hline Herd synchronization status & Mideast & Midwest & Mountain & Northeast & Northwest & Southeast & Southwest & \multicolumn{2}{|c|}{ United States } \\
\hline Not available ${ }^{3} \mathrm{n}$ & 180 & 2,290 & 108 & 1,784 & 11 & 119 & 19 & 4,511 & 34 \\
\hline Possibly synchronized, n & 58 & 285 & 20 & 275 & 9 & 21 & 23 & 691 & 5 \\
\hline Probably synchronized, n & 97 & 975 & 47 & 711 & 13 & 39 & 41 & 1,923 & 14 \\
\hline Synchronized, n & 13 & 175 & 16 & 127 & 2 & 5 & 1 & 339 & 3 \\
\hline $\begin{array}{l}\text { Probable and synchronized } \\
\text { within region, } \%\end{array}$ & 14 & 19 & 17 & 16 & 19 & 10 & 17 & - & 17 \\
\hline
\end{tabular}

${ }^{1}$ Herd synchronization (ovulation synchronization followed by timed AI) status determined using the method of Miller et al. (2007).

${ }^{2}$ Mideast = Delaware, Kentucky, Maryland, North Carolina, Tennessee, Virginia, and West Virginia; Midwest = Illinois, Indiana, Iowa, Michigan, Minnesota, Missouri, Ohio, and Wisconsin; Mountain = Colorado, Kansas, Montana, Nebraska, North Dakota, South Dakota, Utah, and Wyoming; Northeast = Connecticut, Maine, Massachusetts, New Hampshire, New Jersey, New York, Pennsylvania, Rhode Island, and Vermont; Northwest = Alaska, Idaho, Oregon, and Washington; Southeast = Alabama, Arkansas, Florida, Georgia, Louisiana, Mississippi, Oklahoma, Puerto Rico, South Carolina, and Texas; and Southwest = Arizona, California, Hawaii, Nevada, and New Mexico.

${ }^{3}$ Synchronization status could not be determined because herd had $<20$ cows with reported breedings.

Holstein fifth breedings; $P<0.05$ for Jersey fifth breedings); quadratic effects were significant for Holstein first $(P<0.001)$, second $(P<0.001)$, and fourth breedings $(P<0.01)$ and Jersey first breedings $(P<0.01)$.

Mean interval between consecutive breedings was also determined for 2006 breedings (Table 8). Mean interval between first and second breedings $(39.3 \mathrm{~d})$ for Holsteins was nearly 2 complete estrous cycles, but the intervals for successive breedings decreased to $35.6 \mathrm{~d}$ between sixth and seventh breedings. Intervals between consecutive breedings were shorter for Jerseys and decreased from $36.1 \mathrm{~d}$ between first and second breedings to $34.3 \mathrm{~d}$ between sixth and seventh breedings. Linear and quadratic effects of breeding numbers on interval between consecutive breedings were both significant $(P<0.001)$ for Holstein, but only linear effects were significant $(P<0.001)$ for Jerseys.

Means for Holstein reproductive traits differed $(P<$ 0.001 ) by geographical region (Table 9 ). The Northwest had the fewest DFB $(78 \mathrm{~d})$, whereas the Mountain and Mideast regions had the greatest DFB (92 and $91 \mathrm{~d}$, respectively). The Southwest had the highest NRR70 for first breeding (50\%), and the Northwest had the lowest (42\%). The Northeast and Southwest had the highest CR (33\%) and the Northeast had the fewest NB (2.3). In contrast, the Southeast had the lowest CR $(26 \%)$ and the greatest NB (2.7). The Southwest had the fewest DLB $(127 \mathrm{~d})$ and the shortest CI (406 d); the Southeast had the longest CI (440 d), and the greatest DLB was found in the Mountain (157 d) and Mideast and Southeast $(155 \mathrm{~d})$ regions. Oseni et al. (2003) analyzed DO of Holsteins that calved between 1997 and 2002 by state and region and reported that the southeastern United States had the longest DO as well as the largest difference in DO between hot and cold seasons. Mean PR (Table 9) was highest for the Southwest $(28.3 \%)$ and Northwest $(27.9 \%)$ regions and lowest for the Mideast and Southeast (22.2\%) regions.

Table 9 also includes regional SD. The Northwest, which had the lowest mean for DFB, also had the lowest SD (29 d compared with 37 to $46 \mathrm{~d}$ for other regions). In contrast, the SD for NRR70 was 49 or $50 \%$ for all regions. Regional SD for CR increased with CR mean and ranged from 44 to $47 \%$. Regional SD for NB were nearly as large as means for NB and ranged from 1.9 to 2.4 breedings. Within region, SD for DLB and CI were similar (differed by 0 to $2 \mathrm{~d}$ ) except for the Southeast, for which CI SD was $9 \mathrm{~d}$ more than for DLB SD. Regional SD for PR generally decreased as mean PR increased; SD were lowest for the Southwest and Northwest (14.9 and 15.2\%, respectively) and highest for the Southeast and Mountain regions (16.6 and $16.8 \%)$.

To determine if regional differences could have been related to use of synchronized breeding, the method of Miller et al. (2007) was used to categorize US herds with 2006 breedings by region (Table 10). That method requires a herd minimum of 20 cows per year for analysis. Therefore, only 8,857 of the 13,368 Holstein herds with data in Table 9 could be categorized for synchronization status. For Jerseys (not shown), only 35 of the 424 herds eligible for synchronization analysis potentially had synchronized breedings (11 possible, 22 probable, and 2 definite); therefore, the effect of synchronized breeding on reproductive traits was not examined further for Jerseys. For Holsteins, frequency of synchronized breeding (probable and definite) across regions ranged from 10\% (Southeast) to $19 \%$ (Midwest 
Table 11. Means and SD for reproductive traits ${ }^{1}$ of US Holstein cows bred in 2006 by herd synchronization status ${ }^{2}$

\begin{tabular}{|c|c|c|c|c|c|c|c|c|c|c|c|c|}
\hline \multirow[b]{2}{*}{ Herd synchronization status } & \multicolumn{2}{|c|}{$\mathrm{DFB}, \mathrm{d}$} & \multicolumn{2}{|c|}{$\begin{array}{l}\text { NRR70 for first } \\
\text { breeding, } \%\end{array}$} & \multicolumn{2}{|c|}{$\begin{array}{l}\text { CR for first } \\
\text { breeding, \% }\end{array}$} & \multicolumn{2}{|c|}{$\mathrm{NB}, \mathrm{n}$} & \multicolumn{2}{|c|}{ DLB, d } & \multicolumn{2}{|c|}{ CI, d } \\
\hline & Mean & $\mathrm{SD}$ & Mean & $\mathrm{SD}$ & Mean & SD & Mean & $\mathrm{SD}$ & Mean & $\mathrm{SD}$ & Mean & $\mathrm{SD}$ \\
\hline Possibly synchronized & 81 & 35 & 44 & 50 & 29 & 45 & 2.6 & 2.1 & 140 & 86 & 418 & 87 \\
\hline Probably synchronized & 76 & 26 & 40 & 49 & 29 & 45 & 2.8 & 2.2 & 140 & 85 & 417 & 86 \\
\hline Synchronized & 74 & 19 & 39 & 49 & 30 & 46 & 2.8 & 2.2 & 141 & 87 & 417 & 85 \\
\hline
\end{tabular}

${ }^{1} \mathrm{DFB}=$ days between calving and first breeding; NRR70 = nonreturn rate at $70 \mathrm{~d}$ after breeding; $\mathrm{CR}=$ conception rate; NB = number of breedings per lactation; DLB = days between calving and last breeding; and CI = calving interval.

${ }^{2}$ Herd synchronization (ovulation synchronization followed by timed AI) status determined using the method of Miller et al. (2007).

and Northwest) of herds, with a mean of $17 \%$ of US Holstein herds. Miller et al. (2007) reported that the proportion of herds with synchronized first breedings increased from $2 \%$ of herds and cows in 1996 to almost $20 \%$ of herds and $35 \%$ of cows in 2005 . The use of synchronized breeding did not appear to be a primary cause of regional differences for reproductive traits.

Synchronized herds of US Holsteins bred in 2006 (Table 11) had 18 fewer DFB compared with herds with traditional estrus detection (74 vs. 92 d). Synchronized herds also had lower NRR70 by 12 percentage units for first breedings (39 vs. 51\%), lower CR by 2 percentage units for first breedings ( 30 vs. $32 \%$ ), greater NB by 0.4 breedings (2.8 vs. 2.4), fewer DLB by 5 d (141 vs. 146 d), and shorter CI by 7 d (417 vs. 424 d). Synchroniza- tion status was significant $(P<0.001)$ for all 6 traits. Their SD confirm the effectiveness of the method for designating synchronization status. The SD for DFB, a trait that synchronization would affect directly, declined from 44 to $19 \mathrm{~d}$ as the probability that the herd was synchronized increased. Corresponding changes in SD for the other reproductive traits were small but still proportional to differences in means.

Changes in Holstein and Jersey breeding values for DPR since 1960 are shown in Figure 1 using the January 2009 all-breed base. Not surprisingly, a decline in bull genetic merit for DPR preceded the decline for cows. Breed differences in genetic merit for DPR are also evident, which indicates that genetic improvement of cow fertility is possible. Genetic merit for DPR for both

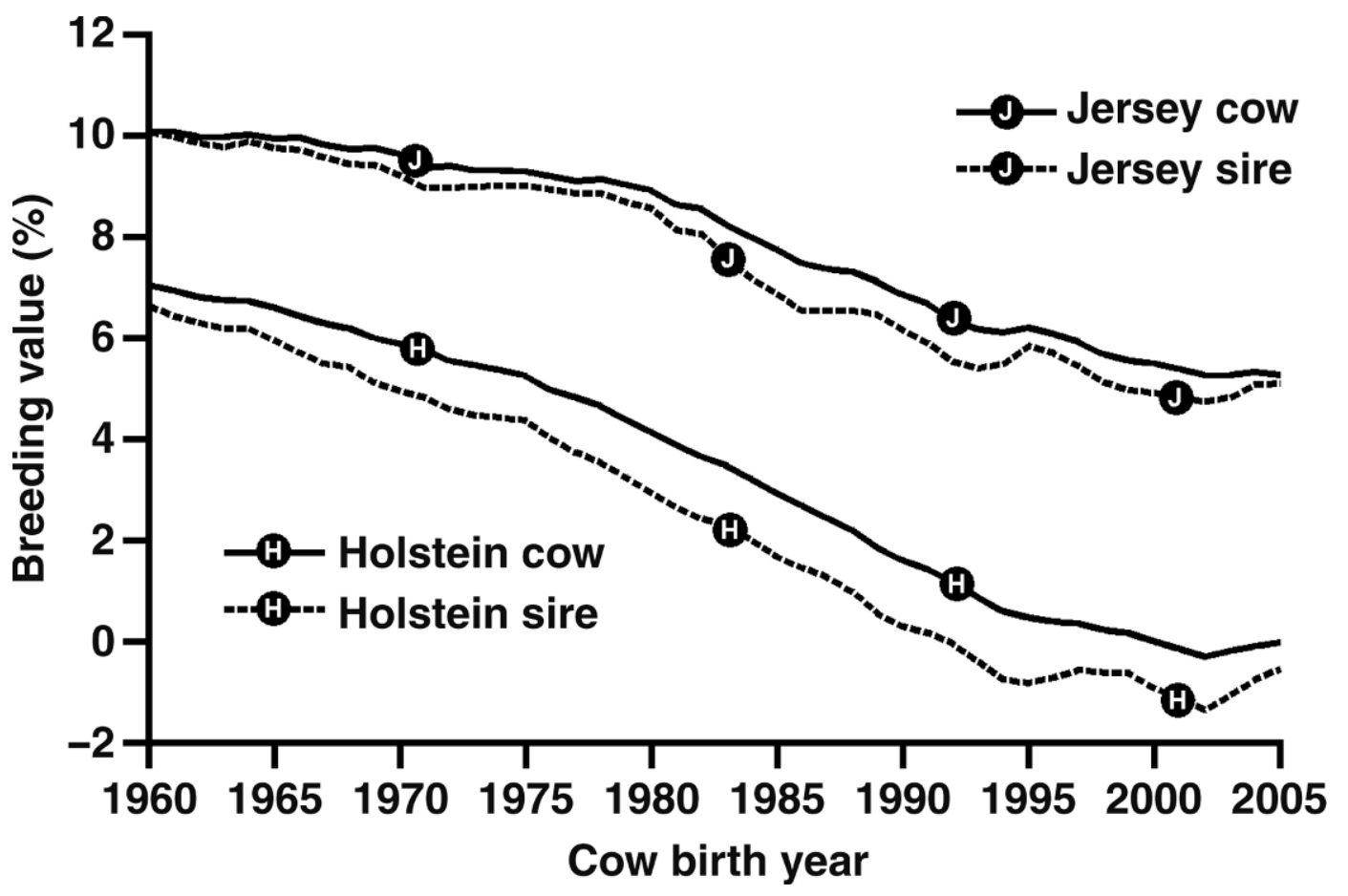

Figure 1. Change in breeding value for daughter pregnancy rate for Holsteins and Jerseys on the January 2009 all-breed base for USDADHIA genetic evaluations. 
breeds showed increases after implementation of genetic evaluations for productive life in 1994 (VanRaden and Wiggans, 1995) and DPR in 2003 (VanRaden et al., 2004). Use of PL evaluations probably helped reverse the genetic decline in PR because of the negative relationship between DO and PL (genetic correlation of -0.59 ; VanRaden et al., 2004). For other reproductive traits, the impact of selection decisions based on PL and DPR evaluations has not been documented. Norman et al. (2008) have shown that bulls of superior genetic merit for DPR, which has a negative relationship with daughter DO, have daughters with reduced culling for reproduction and thus longer productive life.

\section{CONCLUSIONS}

Holstein DFB declined from 94 d in 1997 to 86 d in 2006; a similar trend was not observed for Jerseys, possibly because synchronized breeding is more common in Holstein than Jersey herds. For both breeds, first-breeding NRR70 and first-breeding CR declined, and NB increased. Later parities were associated with greater DFB and lower first-breeding NRR70 and CR compared with early parities for 2006 breedings of both breeds. The NB for 2006 breedings remained constant across parities for Holsteins and increased slightly for Jerseys. First- and second-breeding NRR70 declined for 2006 breedings of both breeds as parity increased. Second-breeding CR was often highest among 2006 breedings within parity for Holsteins but lower than first-breeding CR for Jerseys. For 2006 breedings of both breeds, CR within breeding number generally declined as parity increased. Trends appear to be affected by geographical region and increased use of synchronized breeding. Since 2002, phenotypic performance for CR, DLB, and CI as well as genetic merit for DPR have stopped their historical declines and started to improve.

\section{ACKNOWLEDGMENTS}

The cooperation of AgriTech Analytics (Visalia, CA), AgSource Cooperative Services (Verona, WI), Dairy Records Management Systems (Raleigh, NC, and Ames, IA), and Pennsylvania DHIA (University Park, PA) in supplying breeding reports is acknowledged. Information on AI bulls was provided by AI organizations through the National Association of Animal Breeders. Suggestions made by M. T. Kuhn, formerly of the Animal Improvement Programs Laboratory (Beltsville, $\mathrm{MD}$ ), in formulating $\mathrm{CR}$ were helpful as were the suggestions of the Journal of Dairy Science reviewers.

\section{REFERENCES}

Animal Improvement Programs Laboratory. 2003. Dairy records processing center activity summary, DHI report K-6 for 2002 http://aipl.arsusda.gov/publish/dhi/dhi03/drpcall.html. Accessed January 19, 2009

Animal Improvement Programs Laboratory. 2008. Listing of format 5, reproductive record. http://aipl.arsusda.gov/formats/fmt5.html. Accessed January 15, 2009

Animal Improvement Programs Laboratory. 2009a. Cow genetic trends. http://aipl.arsusda.gov/eval/summary/trend.cfm. Accessed January 29, 2009.

Animal Improvement Programs Laboratory. 2009b. DHI participation as of January 1, 2009, DHI report K-1. http://aipl.arsusda.gov/ publish/dhi/dhi09/partall.html. Accessed February 6, 2009.

Berger, P. J., R. D. Shanks, A. E. Freeman, and R. C. Laben. 1981. Genetic aspects of milk yield and reproductive performance. J. Dairy Sci. 64:114-122.

Burnside, E. B., S. B. Kowalchuk, D. B. Lambroughton, and N. M. MacLeod. 1971. Canadian dairy cow disposals. I. Differences between breeds, lactation numbers and seasons. Can. J. Anim. Sci. 51:75-83.

Clay, J. S., and B. T. McDaniel. 2001. Computing mating bull fertility from DHI nonreturn data. J. Dairy Sci. 84:1238-1245.

De Vries, A. 2006. Economic value of pregnancy in dairy cattle. J. Dairy Sci. 89:3876-3885.

De Vries, A., and C. A. Risco. 2005. Trends and seasonality of reproductive performance in Florida and Georgia dairy herds from 1976 to 2002. J. Dairy Sci. 88:3155-3165.

DeJarnette, J. M., C. G. Sattler, C. E. Marshall, and R. L. Nebel. 2007. Voluntary waiting period management practices in dairy herds participating in a progeny test program. J. Dairy Sci. 90:1073-1079.

Faust, M. A., B. T. McDaniel, and O. W. Robison. 1989. Genetics of reproduction in primiparous Holsteins. J. Dairy Sci. 72:194-201.

Fetrow, J., D. McClary, R. Harman, K. Butcher, L. Weaver, E. Studer, J. Ehrlich, W. Etherington, W. Guterbock, D. Klingborg, J. Reneau, and N. Williamson. 1990. Calculating selected reproductive indices: Recommendation of the American Association of Bovine Practitioners. J. Dairy Sci. 73:78-90.

Hansen, L. B., A. E. Freeman, and P. J. Berger. 1983a. Variances, repeatabilities, and age adjustments of yield and fertility in dairy cattle. J. Dairy Sci. 66:281-292.

Hansen, L. B., A. E. Freeman, and P. J. Berger. 1983b. Yield and fertility relationships in dairy cattle. J. Dairy Sci. 66:293-305.

Hare, E., H. D. Norman, and J. R. Wright. 2004. Duration of herd participation in Dairy Herd Improvement milk recording in the United States. J. Dairy Sci. 87:2743-2747.

Hare, E., H. D. Norman, and J. R. Wright. 2006. Trends in calving ages and calving intervals for dairy cattle breeds in the United States. J. Dairy Sci. 89:365-370.

Heimann, M. M. 1979. AI data and effects of productive and reproductive performance of Israeli dairy cattle. "ON" Artificial Insemination Cooperative, Sarid, Israel.

Hermas, S. A., C. W. Young, and J. W. Rust. 1987. Genetic relationships and additive genetic variation of productive and reproductive traits in Guernsey dairy cattle. J. Dairy Sci. 70:1252-1257.

Hillers, J. K., P. L. Senger, R. L. Darlington, and W. N. Fleming. 1984. Effects of production, season, age of cow, days dry, and days in milk on conception to first service in large commercial dairy herds. J. Dairy Sci. 67:861-867.

Hillers, J. K., S. C. Thonney, and C. T. Gaskins. 1982. Economic comparison of breeding dairy cows artificially versus naturally. J. Dairy Sci. 65:861-865.

International Bull Evaluation Service. 2009. Description of National Genetic Evaluation Systems for dairy cattle traits as applied in different Interbull member countries http://www-interbull.slu. se/national_ges_info2/framesida-ges.htm. Accessed January 19, 2009 . 
Laben, R. L., R. Shanks, P. J. Berger, and A. E. Freeman. 1982. Factors affecting milk yield and reproductive performance. J. Dairy Sci. 65:1004-1015.

Lucy, M. C. 2001. Reproductive loss in high-producing dairy cattle: Where will it end? J. Dairy Sci. 84:1277-1293.

McGilliard, M. L. 1978. Net returns from using genetically superior sires. J. Dairy Sci. 61:250-254.

Miller, R. H., H. D. Norman, M. T. Kuhn, J. S. Clay, and J. L. Hutchison. 2007. Voluntary waiting period and adoption of synchronized breeding in Dairy Herd Improvement herds. J. Dairy Sci. 90:1594-1606.

Norman, H. D., J. L. Hutchison, J. R. Wright, and M. T. Kuhn. 2007. Selection of yield and fitness traits when culling Holsteins during the first three lactations. J. Dairy Sci. 90:1008-1020.

Norman, H. D., R. L. Powell, J. R. Wright, and C. G. Sattler. 2003. Timeliness and effectiveness of progeny testing through artificial insemination. J. Dairy Sci. 86:1513-1525.

Norman, H. D., J. R. Wright, M. T. Kuhn, S. M. Hubbard, J. B. Cole, and P. M. VanRaden. 2009. Genetic and environmental factors that impact gestation length in dairy cattle. J. Dairy Sci. 92:2259-2269

Norman, H. D., J. R. Wright, and R. H. Miller. 2008. Impact of selection for increased daughter fertility on productive life and culling for reproduction. J. Dairy Sci. 91(E-Suppl. 1):7. (Abstr.)

O'Bleness, G. V., and L. D. Van Vleck. 1962. Reasons for disposal of dairy cows from New York herds. J. Dairy Sci. 45:1087-1093.

Olds, D., T. Cooper, and F. A. Thrift. 1979. Relationships between milk yield and fertility in dairy cattle. J. Dairy Sci. 62:11401144.

Oseni, S., I. Misztal, S. Tsuruta, and R. Rekaya. 2003. Seasonality of days open in US Holsteins. J. Dairy Sci. 86:3718-3725.
Philipsson, J. 1981. Genetic aspects of female fertility in dairy cattle. Livest. Prod. Sci. 8:307-319.

Risco, C. A., F. Lima, M.-J. Thatcher, and W. W. Thatcher. 2008. If you use bulls. Hoard's West 10:W44.

Shanks, R. D., and A. E. Freeman. 1979. Postpartum distribution of health costs and health disorders in Holstein cows. J. Dairy Sci. 62(Suppl. 1):87 (Abstr.).

USDA. 2007. Dairy 2007, Part I: Reference of Dairy Cattle Health and Management Practices in the United States, 2007. USDA-APHISVS, CEAH, Fort Collins, CO.

USDA. 2008. Dairy 2007, Part II: Changes in the U.S. Dairy Cattle Industry, 1991-2007. USDA-APHIS-VS, CEAH. Fort Collins, $\mathrm{CO}$.

Van Vleck, L. D., and H. D. Norman. 1972. Association of type traits with reasons for disposal. J. Dairy Sci. 55:1698-1705.

VanRaden, P. M., A. H. Sanders, M. E. Tooker, R. H. Miller, H. D. Norman, M. T. Kuhn, and G. R. Wiggans. 2004. Development of a national genetic evaluation for cow fertility. J. Dairy Sci. $87: 2285-2292$.

VanRaden, P. M., M. E. Tooker, J. B. Cole, G. R. Wiggans, and J. H. Megonigal Jr. 2007. Genetic evaluations for mixed-breed populations. J. Dairy Sci. 90:2434-2441.

VanRaden, P. M., and G. R. Wiggans. 1995. Productive life evaluations: Calculation, accuracy, and economic value. J. Dairy Sci. 78:631638.

Washburn, S. P., W. J. Silvia, C. H. Brown, B. T. McDaniel, and A. J. McAllister. 2002. Trends in reproductive performance in southeastern Holstein and Jersey DHI herds. J. Dairy Sci. $85: 244-251$. 